\title{
Protein expression profiling of the shrimp cellular response to white spot syndrome virus infection
}

\author{
Hao-Ching Wang ${ }^{\mathrm{a}, \mathrm{b}}$, Han-Ching Wang ${ }^{\mathrm{c}}$, Jiann-Horng Leu ${ }^{\mathrm{c}}$, Guang-Hsiung Kou ${ }^{\mathrm{c}}$, \\ Andrew H.-J. Wang ${ }^{\mathrm{a}, \mathrm{b}, \mathrm{d}, * *}$, Chu-Fang Lo ${ }^{\mathrm{c}, *}$ \\ anstitute of Biochemical Sciences, National Taiwan University, Taipei 106, Taiwan, ROC \\ ${ }^{\mathrm{b}}$ Institute of Biological Chemistry, Academia Sinica, Taipei 115, Taiwan, ROC \\ ${ }^{\mathrm{c}}$ Institute of Zoology, National Taiwan University, Taipei 106, Taiwan, ROC \\ ${ }^{\mathrm{d}}$ Core Facilities for Proteomics Research, Academia Sinica, Taipei 115, Taiwan, ROC
}

Received 5 October 2006; received in revised form 30 October 2006; accepted 1 November 2006

Available online 5 December 2006

\begin{abstract}
To better understand the pathogenesis of white spot syndrome virus (WSSV) and to determine which cell pathways might be affected after WSSV infection, two-dimensional gel electrophoresis (2-DE) was used to produce protein expression profiles from samples taken at $48 \mathrm{~h}$ post-infection (hpi) from the stomachs of Litopenaeus vannamei (also called Penaeus vannamei) that were either specific pathogen free or else infected with WSSV. Seventy-five protein spots that consistently showed either a marked change $(>50 \%)$ in accumulated levels or else were highly expressed throughout the course of WSSV infection were selected for further study. After in-gel trypsin digestion followed by LC-nanoESI-MS/MS, bioinformatics databases were searched for matches. A total of 53 proteins were identified, with functions that included energy production, calcium homeostasis, nucleic acid synthesis, signaling/communication, oxygen carrier/transportation, and SUMO-related modification. 2-DE results were shown to be consistent with relative EST database data from a previously developed EST database of two Penaeus monodon cDNA libraries. For seven selected genes, 2-DE and EST data were also compared with transcriptional time-course RT-PCR data. This study is the first global analysis of differentially expressed proteins in WSSV-infected shrimp, and in addition to increasing our understanding of the molecular pathogenesis of this virus-associated shrimp disease, the results presented here should be useful both for identifying potential biomarkers and for developing antiviral measures.
\end{abstract}

(C) 2006 Elsevier Ltd. All rights reserved.

Keywords: WSSV infection; Protein expression profiling; Host response; Proteomic analysis; White spot syndrome virus

\section{Introduction}

**Also to be corresponded to: Institute of Biological Chemistry, Academia Sinica, Taipei 115, Taiwan, ROC.

Tel.: + 88622788 1981; fax: + 886227882043 .

*Corresponding author. Tel.: + 886223633562 ; fax: +886223638179 .

E-mail addresses: ahjwang@gate.sinica.edu.tw (A.H.-J. Wang), gracelow@ntu.edu.tw (C.-F. Lo).
White spot syndrome (WSS) is a lethal disease that affects cultured shrimp species and many other crustaceans [1-9]. In farmed shrimp, the virus can cause $100 \%$ cumulative mortality in $2-10$ days. The causative agent of WSS is an enveloped, ellipsoid, large $(\sim 300 \mathrm{~kb})$, double stranded DNA virus known 
as white spot syndrome virus (WSSV) [10-12]. WSSV has many unique properties. In addition to many non-standard proteins with functions that are not yet known, WSSV was also recently shown to have at least 39 structural proteins [13,14], one of which, WSSV664 is the largest viral protein reported to date [15]. WSS has been formally recognized since 1992 , but it was only recently that the virus was designated by the International Committee on the Taxonomy of Viruses as the type species of a new genus, Whispovirus, family Nimaviridae [16].

To understand the pathogenesis of any disease, knowledge of the interactions between virus and host is critical. Virus-host interactions may result in immune responses against the invader, and may also result in changes in the expression levels of host genes that favor virus replication. To date, virushost interactions of WSSV have been studied at the transcription level using expressed sequence tags (ESTs), RT-PCR, microarray chips, suppression subtractive hybridization and differential hybridization [17-24]. However, many of these studies focused on immune cells (lymphoid organ cells and hemocytes) and although this has provided good insights into biodefense mechanisms, these immune-related cells are not primary WSSV targets [25-27], and their cellular pathways are, therefore, not necessarily representative of the host cells in which virus replication occurs. Further, even those studies that investigated the modulation of protein expression were not global but instead focused mainly on only a few immune-related defense genes such as beta-glycan-binding protein [28-30]. In consequence, little is known about the cellular events associated with WSSV infection in permissive cells. In the present paper we, therefore, use comparative proteomics to identify proteins whose accumulated levels in stomach cells (a main target organ of WSSV) are altered significantly after WSSV infection. Identifying these proteins is an important first step toward improving our understanding of the cellular pathways that are necessary for WSSV infection.

Our basic approach was to use two-dimensional electrophoresis (2-DE) [31] with immobilized $\mathrm{pH}$ gradients (IPG) [32] to produce protein profiles for stomach cells from specific pathogen free (SPF) and WSSV-infected Litopenaeus vannamei (also called Penaeus vannamei). In addition to an invariable control (beta-actin), proteins that were either markedly up- or down-regulated or else were highly expressed throughout WSSV infection were then identified by in-gel trypsin digestion followed by LC-nanoESI-MS/MS and a search of bioinformatics databases. ESTs and RT-PCR were used to confirm that changes in transcription levels over time were in good agreement with the accumulated protein (i.e. translation level) results given by the proteomic analysis. Lastly, we look at which cellular pathways might be altered and discuss the physiological implications of these results.

\section{Materials and methods}

\subsection{Virus, virus inoculum and experimental animals}

The virus used in this study, WSSV T-1 isolate (GenBank accession number AF440570) [8,33], was prepared from a batch of WSSV-infected Penaeus monodon collected in Taiwan in 1994. To prepare the WSSV inoculum, we first selected one of the original, frozen $\left(-80^{\circ} \mathrm{C}\right) 1994 \mathrm{P}$. monodon specimens that tested PCR positive for WSSV, but tested negative for other shrimp viruses (infectious hypodermal and haematopoietic necrosis virus [IHHNV], Taura syndrome virus [TSV], yellowhead disease virus/gill associated virus [YHV/GAV], P. monodon-type baculovirus [PMBV], mourilyan virus) using commercial PCR detection kits (Farming IntelliGene Tech. Corp., Taiwan). Carapace and integument tissues $(0.5 \mathrm{~g})$ from this frozen specimen (body weight $30 \mathrm{~g}$ ) were minced and then homogenized in $4.5 \mathrm{ml}$ of sterile PBS buffer. After centrifugation $\left(400 \mathrm{~g}, 10 \mathrm{~min}, 4^{\circ} \mathrm{C}\right)$, the supernatant was filtered through a $0.45 \mu \mathrm{m}$ membrane and used immediately to infect an adult, SPF $L$. vannamei (body weight $45 \mathrm{~g}$; High Health Aquaculture. Inc, Hawaii) by injection $(200 \mu \mathrm{l})$ as described previously [26]. At 24 hours post-infection (hpi), hemolymph was extracted from this moribund shrimp, diluted $4 \times$ with phosphate-buffered saline (PBS; $137 \mathrm{mM}$ $\mathrm{NaCl}, \quad 2.7 \mathrm{mM} \quad \mathrm{KCl}, \quad 10 \mathrm{mM} \quad \mathrm{Na}_{2} \mathrm{HPO}_{4}, \quad 2 \mathrm{mM}$ $\mathrm{KH}_{2} \mathrm{PO}_{4}$ ), and frozen at $-80^{\circ} \mathrm{C}$ for use as virus stock. The experimental inoculum was then prepared from the supernatant of this stock after centrifugation at $400 \mathrm{~g}$ for $10 \mathrm{~min}$ at $4{ }^{\circ} \mathrm{C}$ and further dilution $\left(10^{-2}\right)$ with PBS [34].

Since it is still very difficult to acquire $P$. monodon specimens that are SPF, the experimental shrimp for the 2-DE/MS studies were the SPF offspring (mean body weight $2.6 \mathrm{~g}$ ) of SPF $L$. vannamei brooders purchased from High Health Aquaculture, Inc., Hawaii. These shrimp were bred and cultured at the 
Marine Research Station, Academia Sinica, Taiwan. The disease-free status of randomly selected samples of the experimental shrimp was confirmed using the same commercial PCR detection kits for WSSV, IHHNV, TSV, YHV/GAV, PMBV and mourilyan virus (see above), and the shrimp were then challenged with WSSV $(100 \mu \mathrm{l} /$ shrimp) by intramuscular injection following Tsai et al. [26]. Shrimp injected with PBS vehicle only were used as controls. The experimental shrimp $(n=480)$ were kept in 2.51 tanks (30 shrimp/tank) containing filtered, aerated seawater (33\% salinity; 1.81 seawater/tank) at constant temperature $\left(28 \pm 1{ }^{\circ} \mathrm{C}\right)$. Every $8 \mathrm{~h}$, the tanks were checked, and dead and moribund shrimp were removed. A parallel study (data not shown) found that cumulative mortality reached $40-50 \%$ at $48 \mathrm{hpi}$, and at this time, the stomachs (and other tissues) of the active (as opposed to moribund) surviving infected and control shrimps in all but 4 of the tanks were collected and frozen using liquid nitrogen. For the time-course study, SPF L. vannamei offspring ( $n=40$; mean body weight $9 \mathrm{~g}$ ) were experimentally infected using the method described above, and sample specimens were collected at $0,6,12$ and 36 hpi.

\subsection{Two-dimensional electrophoresis}

For each 2-DE, the frozen stomachs from three shrimp were ground to a fine powder at $-80^{\circ} \mathrm{C}$. The powder was then suspended in a three-fold dilution of PBS buffer containing protease inhibitor cocktail (applied according to the manufacturer's protocol, Roche Diagnostics, Mannheim, Germany). After centrifugation at $3000 \mathrm{~g}\left(30 \mathrm{~min}, 4{ }^{\circ} \mathrm{C}\right)$, the supernatant was collected and a TCA/DTT mixture was added (final concentration: $10 \% \mathrm{w} / \mathrm{v}$ TCA and $0.1 \%$ DTT). After standing on ice for $30 \mathrm{~min}$ and another centrifugation $\left(10,000 \mathrm{~g}, 30 \mathrm{~min}, 4{ }^{\circ} \mathrm{C}\right)$, the supernatant was discarded and the pellet resuspended in acetone containing $0.1 \%$ DTT. The sample was spun again $\left(10,000 \mathrm{~g}, 30 \mathrm{~min}, 4{ }^{\circ} \mathrm{C}\right)$, and the pellet-dried under vacuum and then solubilized in rehydration buffer $(9.8 \mathrm{M}$ urea, $2 \%$ CHAPS, $20 \mathrm{mM}$ DTT, 0.5\% IPG buffer [pH 4-7 or 3-10; Amersham Biosciences]). After a final centrifugation $\left(10,000 \mathrm{~g}, 30 \mathrm{~min}, 15^{\circ} \mathrm{C}\right)$, the supernatant, which contained the soluble protein fraction, was used as a 2-DE sample. Protein concentration of 2-DE samples was estimated using a 2-D Quant Kit (Amersham Biosciences).
The first dimension of the 2-DE, isoelectric focusing (IEF), was performed in $13 \mathrm{~cm}$ Immobiline DryStrip gel (Amersham Biosciences) using an integrated system, the Ettan IPGphor (Amersham Biosciences), where rehydration with the sample and IEF are performed automatically. Two $\mathrm{pH}$ gradient strips were used: linear $\mathrm{pH} \mathrm{4-7}$ and 3-10. Each sample $(250 \mu \mathrm{g}$ protein) was dissolved in $250 \mu \mathrm{l}$ rehydration buffer with a trace of bromophenol blue and placed in the base well of an IPGphor stripholder. An IPG strip was then placed on the top of the sample, and after rehydration in the IPGphor $(16 \mathrm{~h}$ at $50 \mathrm{~V})$, automatic IEF was performed using the following step voltage focusing protocol: $1 \mathrm{~h}$ at $300 \mathrm{~V}, 1 \mathrm{~h}$ at $500 \mathrm{~V}, 2 \mathrm{~h}$ at $1000 \mathrm{~V}, 2 \mathrm{~h}$ at $4000 \mathrm{~V}$ and $10 \mathrm{~h}$ at $8000 \mathrm{~V}$. All the above procedures were carried out at $20^{\circ} \mathrm{C}$. After the first dimensional IEF, the IPG strips were equilibrated in a sodium dodecyl sulfate (SDS) equilibration buffer (6 M urea, 2\% SDS, 30\% glycerol, $50 \mathrm{mM}$ Tris- $\mathrm{HCl}, \mathrm{pH} 8.8$ ) containing $1 \%$ DTT for $15 \mathrm{~min}$. The IPG gel strips were then removed to another equilibration buffer containing $2.5 \%$ iodoacetamide and equilibrated for a further $15 \mathrm{~min}$. The equilibrated IPG strips were then placed onto a polyacrylamide gel that consisted of $14 \%$ acrylamide, $\mathrm{pH} 8.8$, for the separating gel, and $4 \%$ acrylamide, pH 6.8 , for the stacking gel. The second dimensional separation was run at $20 \mathrm{~mA}$ per gel at $15^{\circ} \mathrm{C}$ for 5-6h. At the end of each run, the gels were stained with sypro ruby, and the protein patterns of the gels were scanned using a Typhoon 9400 scanner (Amersham Biosciences). Gel image matching was done using PDQuest software (Bio-Rad).

\subsection{In-gel protein digestion and protein identification}

Protein spots of interest were manually excised from the gels, washed twice with $25 \mathrm{mM}$ ammonium bicarbonate buffer ( $\mathrm{pH} 8.5)$ in $50 \%$ acetonitrile, for $15 \mathrm{~min}$ each time, dehydrated with $100 \%$ acetonitrile for $5 \mathrm{~min}$, vacuum dried, and rehydrated with $100 \mathrm{ng}$ of sequencing-grade, modified trypsin (Promega) in $25 \mathrm{mM}$ ammonium bicarbonate, $\mathrm{pH} 8.5$, at $37^{\circ} \mathrm{C}$ for $16 \mathrm{~h}$. Following digestion, tryptic peptides were extracted twice with $5 \%$ formic acid in $50 \%$ acetonitrile for $15 \mathrm{~min}$ each time with sonication. The extracted solutions were pooled and evaporated to dryness under vacuum. Samples were dissolved in $0.1 \%$ formic acid in $50 \%$ acetonitrile and analyzed by LC-nanoESI-MS/MS. Proteins were identified by $\mathrm{MS} / \mathrm{MS}$ ion search using the search program 
MASCOT and the NCBI protein and EST sequence databases. For MS/MS ion search, the mass tolerance parameter was $0.25 \mathrm{Da}, \mathrm{MS} / \mathrm{MS}$ ion mass tolerance was $0.25 \mathrm{Da}$, and up to one missed cleavage was allowed. Variable modifications considered were methionine oxidation and cysteine carboxyamidomethylation. Significant hits (as defined by Mascot probability analysis) were regarded as positive identification.

\subsection{EST-based transcription analysis of identified protein genes}

This analysis used two cDNA libraries, PmTwI (WSSV-infected) and PmTwN (non-infected). To construct these libraries, RNA was extracted from P. monodon postlarvae (PL20) that had either been exposed to WSSV by immersion $66 \mathrm{~h}$ previously (for PmTwI), or else were left unchallenged (for PmTwN). From the extracted RNA, cDNA was synthesized by RT-PCR, and the two libraries were then constructed using a $\lambda$-Zap II vector construction kit (Stratagene), followed by conversion to the pBluescript plasmid by mass excision according to the manufacturer's instructions. From these libraries, a total of 14152 ESTs (7335 from PmTwI; 6817 from PmTwN) were generated by subjecting randomly selected clones to $3^{\prime}$ sequencing. The raw traces were base-called by running Phred $(Q>13)$, and the resultant sequences were then masked for pBluescript vector and WSSV (AF440570) using the "Cross_match" package with default parameters (minimatch 12, penalty -2 , minscore 20). The Prap assembly program produced a total of 2183 and 2075 unique sequences from PmTwI and PmTwN, respectively, and these were then checked for matches in the GeneBank $n r$ (non-redundant) peptide sequence databases (http://www.ncbi. nlm.nih.gov) and SWISS PROT (http://www.ebi. ac.uk/swissprot/) using BlastX and InterPro Scan with default parameters. After checking, there were still 2155 unique sequences that remained unmatched, but these were further subjected to $5^{\prime}$ sequencing and analysis as above, and ultimately all but 1056 unique sequences were successfully identified. After the genes had been identified, the gene ontology (GO) database (http://www.geneontology. org/) was used to classify the ESTs by biological process, cellular component, and molecular function. In addition, the Kyoto Encyclopedia of Genes and Genomes (KEGG http://bioinfo.weizmann. ac.il:3456/kegg/kegg.html) [35] was used to classify the genes according to their biochemical roles. To identify genes that might be differentially expressed, the number of EST clones that matched the gene in each library was expressed as a percentage relative to the total number of ESTs in the same library.

\subsection{Time-course $R T$ - $P C R$}

WSSV-challenged L. vannamei were sampled at 0 (i.e., immediately before infection), 6, 12 and $36 \mathrm{hpi}$. Total RNA was extracted from the stomachs of the $L$. vannamei harvested at each time point. The stomachs $(n=3)$ from each time point were pooled, purified with TRIzol Reagent (Invitrogen) and then treated with RNase-free DNase I (Roche) to remove any residual DNA. First strand cDNA synthesis was performed using the oligo-dT primer, and $2 \mu \mathrm{l}$ $(1 \mu \mathrm{g})$ of the cDNA was subjected to PCR in a $50-\mu 1$ reaction mixture containing an appropriate primer pair (Table 1). For comparison, an ICP11 gene fragment was also amplified from the same templates by the primer pairs ICP11-F/ICP11-R. A shrimp beta-actin primer set, actinF1/actinR1, was used as an internal control for RNA quality and amplification efficiency. To confirm there was no WSSV DNA contamination of the RNA samples, a WSSV genomic DNA-specific primer pair, IC-F2/ IC-R3, derived from an intergenic region of the WSSV genome, was also used as a quality control.

\section{Results}

\subsection{2-DE analysis and protein identification of protein spots in stomach cells of WSSV-infected shrimp}

Mortality among the WSSV-infected shrimp approached $50 \%$ at $48 \mathrm{hpi}$ and at this time, the stomachs of surviving PBS control (mock-infected) and WSSV-infected shrimp were collected and subjected to 2-DE. After staining with sypro ruby, automatic detection of the protein profiles revealed 500 protein spots (Fig. 1). A total of 75 eligible spots (i.e. spots that were present in three replicates) were subjected to LC-nanoESI-MS/MS and submitted to database searches for peptide matching and protein identification. Table 2 showed the 53 protein spots that were successfully identified. Some proteins were identified in more than one spot (e.g. glyceraldehydes-3-phosphate dehydrogenase in spots 37,38 and 43). For the known proteins, the experimental 
Table 1

Primers used in temporal RT-PCR analysis

\begin{tabular}{lll}
\hline Target gene & Primer name & Primer sequence $\left(5^{\prime}-3^{\prime}\right)$ \\
\hline Glycoaldehyde-3-phosphate dehydrogenase & GAPDH-F & $5^{\prime}$-CGAGTGCTCCTACGATGATCAAGG-3' \\
& GAPDH-R & $5^{\prime}$-GTACTTAGCGTCGAAGATGGAGGACC-3' \\
Fructose-bisphosphate aldolase & Aldolase-F & $5^{\prime}$-CAACGTTGAGAACACCGAGGAGAACC-3' \\
& Aldolase-R & $5^{\prime}$-GTTCTTGCCGATCTTCAGGACACAGC-3 \\
Enolase & Enolase-F & $5^{\prime}$-CAACCAGATTGGCAGTGTGACAGAGTC-3' \\
& Enolase-R & $5^{\prime}$-CAAACTTAGCATTGCCTCCAAGCTCCTCC-3' \\
Cytochrome C oxidase polypeptide VIb & COX6b-F & $5^{\prime}$-GCATATGTCTGAGGAAGCTAAAATGGAAACTG-3' \\
& COX6b-R & $5^{\prime}$-CCTCGAGTCCTGGGAAGATTCCATTATC-3' \\
Calcium-binding protein alpha-B and -A chains, SCP alpha chain & CBP-F & $5^{\prime}$-CCAGGGCAAGAAATACGGCGAATTCC-3' \\
& CBP-R & $5^{\prime}$-CGCTGCAAGACTCATCAGGGTTGG-3' \\
ICP11 & ICP11-F & $5^{\prime}$-CCATATGGCCACCTTCCAGACTGAC-3' \\
Beta actin & ICP11-R & $5^{\prime}$-CCTCGAGTTCTGTTGTTGGCACAATC-3' \\
& Actin-F & $5^{\prime}$-GAYGAYATGGAGAAGATCTGG-3' \\
\hline
\end{tabular}

and theoretical MW and pI were mostly in close agreement (Table 2).

\subsection{Differential analysis of WSSV-infected and mock-infected stomach cells}

For normalization purposes, we regarded beta actin as an invariable protein in response to WSSV infection because its mean intensity (spot 20) in the four replicates for the PBS controls $(96,497$; $15,246,292 ; \quad 18,453,858 ; \quad 15,785,132 ; \quad$ mean $=$ $12,395,445$ ) was always very close (within $5 \%$ ) to the four corresponding replicates for the WSSVinfected samples $(99,023 ; 16,145,483 ; 19,094,090$; $17,171,348$; mean $=13,127,486$ ). To normalize the spot intensities before they were compared, the intensity of each protein spot as measured in the gels was corrected by reference to the beta-actin protein intensity in the same gel. The changes in accumulated protein levels for the 53 spots were presented as ratios ( \pm standard deviation) that represent the normalized, accumulated protein expression levels at 48 hpi relative to the mock-infected PBS controls. As shown in Table 2, WSSV infection for $48 \mathrm{~h}$ caused no change (defined as $<50 \%$ change, ratios between 0.67 and 1.5) for 24 spots, while the other 27 spots showed at least a 50\% increase (ratios $>1.5$ ) or decrease (ratios $<0.67$ ) in intensity.

The differentially expressed genes in the stomach included only one WSSV gene, the non-structural protein ICP11 (spot1), which was strikingly increased. Differentially expressed host genes had functions that included: chitin and chitodextrin hydrolysis (up-regulation of chitinase [spot 3]); carbohydrate metabolism and/or energy production (up-regulation of cytochrome oxidase polypeptide VIb [spot 16], enolase [spots 32 and 33], the alpha and beta subunits of mitochondrial ATP synthase [spots 7 and 47], triosephosphate isomerase [spot 24; but spot 31 was unchanged], glyceraldehydes-3phosphate dehydrogenase [spots 37 and 38; but spot 43 was unchanged] and fructose biphosphate aldolase [spot 41 ; but spots 42 and 48 were unchanged]); nucleic acid synthesis (up-regulation of nucleoside diphosphate kinase [spot 46]); the major pathway for metabolite flux through the mitochondrial outer membrane (up-regulation of voltage-dependent anion-selective channel protein 2 [spot 51]); signaling/communication (up-regulation of a 14-3-3 like protein [spot 11] and a putative activated protein kinase $\mathrm{C}$ receptor [spot 50]); oxygen carrier/transportation (up-regulation of hemocyanin [spot 28]); structure/mobility (up-regulation of Rab GDP dissociation inhibitor [spot 18] and down-regulation of calponin [spot 45]); tricarboxylic-acid (TCA) cycle (up-regulation of aconitase [spot 27] and isocitrate dehydogenase [spot 30]); calcium homeostasis (up-regulation of sarco/endoplasmic reticulum (ER)-type calcium-transporting ATPase [spot 6], and down-regulation of a calcium 


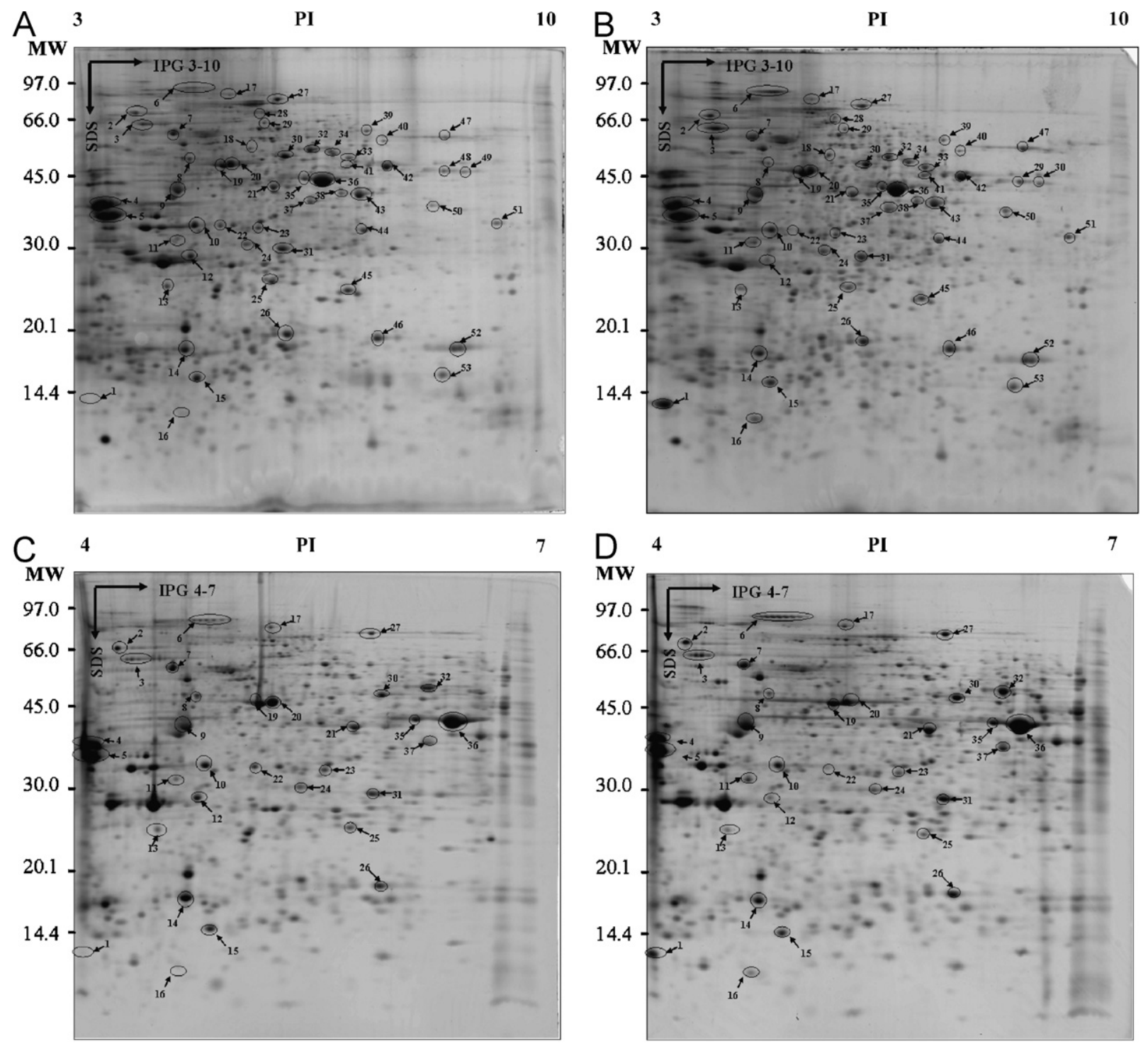

Fig. 1. 2-DE protein profiles of the stomachs of experimental shrimp. (A) IPG 3-10, PBS control, (B) IPG 3-10, WSSV infected, (C) IPG 4-7, PBS control, (D) IPG 4-7, WSSV infected. Eligible protein spots that showed consistent expression change or were constant during WSSV infection are circled. Numbers correspond to the entries in Table 2.

binding protein of the invertebrate sarcoplasmic calcium-binding protein (SCP) family [spot 13]); calcium binding chaperone (up-regulation of calreticulin [spot 2]); SUMO related modification (down-regulation of a small ubiquitin-like modifier [spot 14]); carotenoid astaxanthin binding (downregulation of crustacyanin A2 subunit [spot 25]); and digestion related activity (down-regulation of trypsin [spot 4], carboxypeptidase B [spot 8] and chymotrypsin [spot 12]).
WSSV infection did not affect the accumulated levels of several other important proteins with functions that include cellular components (tropomyosin isoforms [spot 9], beta-actin [spot 20] and actin-depolymerizing factor [spot 26]), the ATP buffering system/resistance to environmental stresses (cytosolic malate dehydrogenase [spots 21 and 23] and arginine kinase [spots 35 and 36]), protein folding activity (protein disulfide isomerase [spot 29]), transportation (intracellular fatty acid-binding 


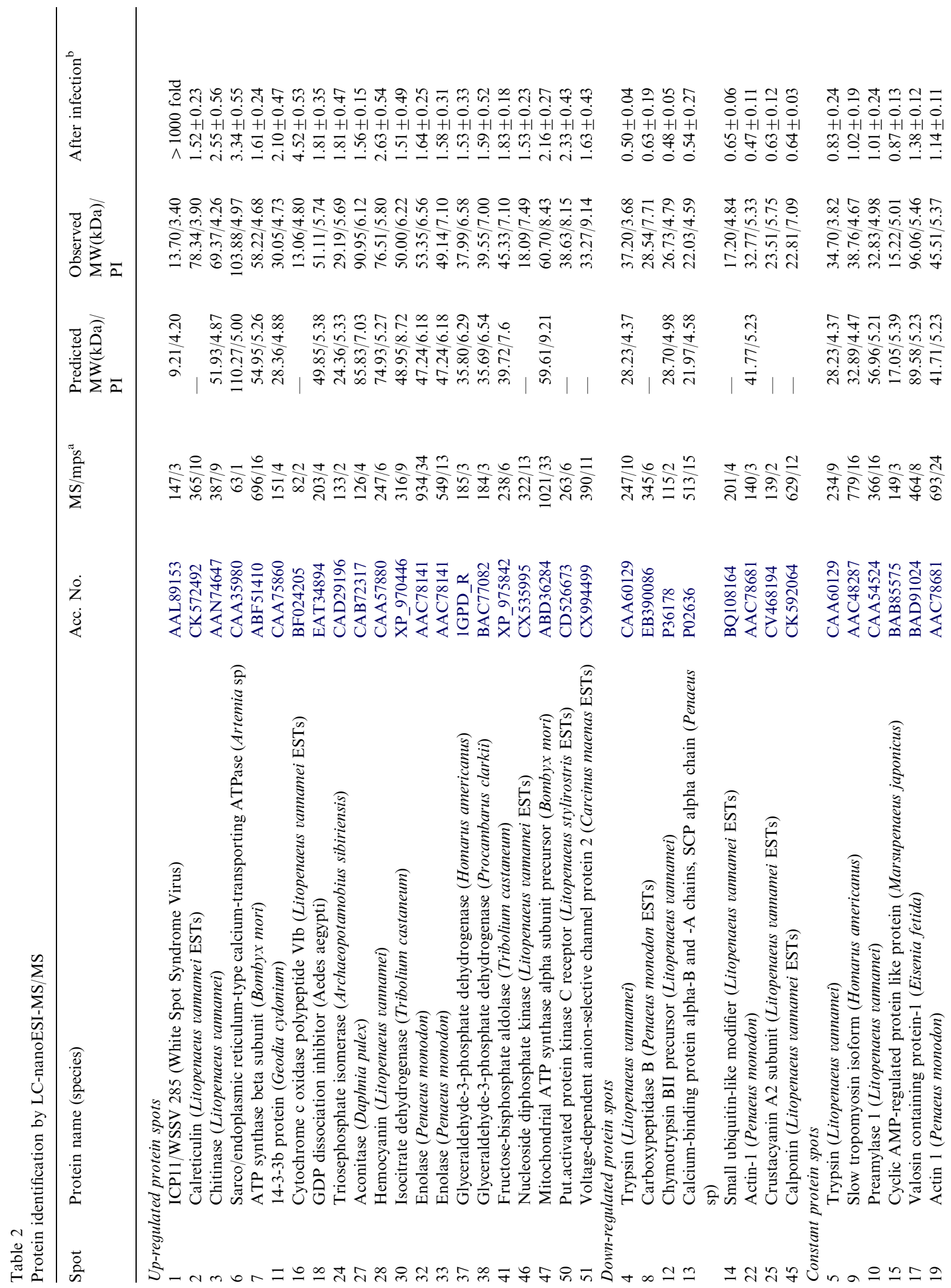


$8=0 \%$

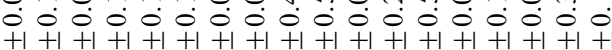

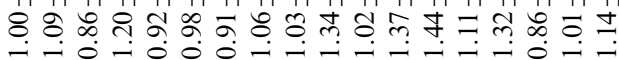

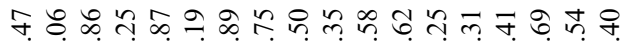

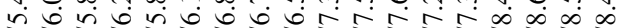

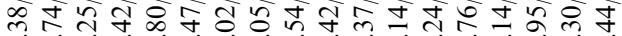

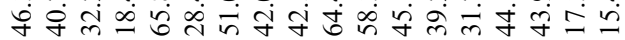

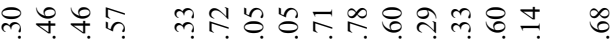
के

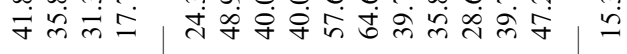

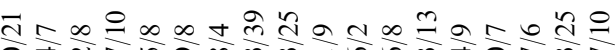

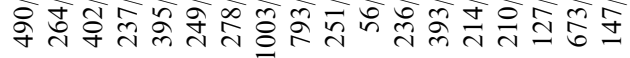

そิ के

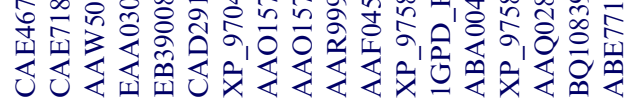

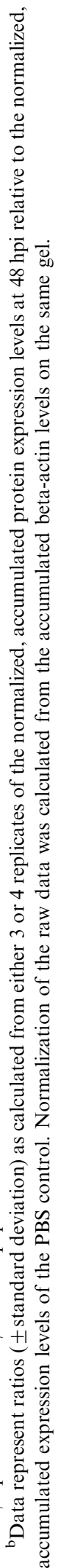


protein [spot 53]), antioxidant activity (catalase [spot 39]) and amino acid catabolism (aspartate aminotransferase [spot 49]).

\subsection{EST analysis of gene transcription levels}

Out of the 53 protein spots that were identified, 39 spots (a total of 30 genes) were cross-referenced in two $P$. monodon cDNA libraries and EST databases, PmTwI and PmTwN (Table 3). The relative EST abundances of 11 of these protein genes were quite consistent with the corresponding changes in accumulated protein levels in Table 2, namely: the increased transcription levels of enolase, fructose biphosphate aldolase, glyceraldehyde3-phosphate dehydrogenase (GAPDH), mitochondrial ATP synthase and nucleotide diphosphate kinase; the decreased transcriptional level of calcium-binding protein alpha chain, SUMO proteins, carboxypeptiase B, chymotrypsin BI, trypsin and crustacyanin A2. From this we conclude that regulation of the accumulated protein levels of these genes is mediated by regulation at the transcription stage. We note, however, that for two genes, the data were inconsistent in the two tables: tropomyosin and intracellular fatty acid-binding protein were both down-regulated according to Table 3, but their protein levels were unchanged in Fig. 1 and Table 2. Other genes (including phosphoglycerate mutase and calreticulin) were not sufficiently well represented in the EST databases to derive meaningful data.

\subsection{Time-course transcriptional and translational analysis of selected differentially expressed genes}

Time-course RT-PCR assays were used to confirm the expression levels of several genes that were consistently up- or down-regulated in both the proteomic analysis and EST database analysis. Three of the selected up-regulated genes were for three enzymes in the glycolytic pathway (glyceraldehydes3-phosphate dehydrogenase, fructose biphosphate aldolase and enolase). Also selected were the downregulated gene for the calcium-binding protein SCP alpha chain, the energy production-related gene for cytochrome $\mathrm{c}$ oxidase polypeptide $\mathrm{VIb}$ (which had up-regulated protein levels [Table 2], but which was only represented once in the EST databases), and the WSSV gene for the nonstructural protein ICP11. The differential mRNA levels of these genes in the time-course RT-PCR
(Fig. 2) showed that the transcription levels of the calcium-binding protein decreased dramatically at the late phase (12 and $36 \mathrm{hpi}$ ), which is in good agreement with the two-fold decrease found in the EST and proteomic analyses. The other RT-PCR results were also in broad agreement with the EST and proteomic analyses: GAPDH and fructose biphosphate aldolase and enolase-produced transcripts that increased at $6 \mathrm{hpi}$ and remained fairly constant thereafter, and increases in the cytochrome c oxidase subunit VIb and WSSV nonstructural protein ICP 11 transcripts were also observed.

The 2-DE time course results for the same 7 genes (Figs. 3A and B) are also broadly in agreement with the proteomic, EST and RT-PCR analyses. The expression levels of GAPDH (spots 37 and 38), fructose biphosphate aldolase (spot 41), enolase (spots 32 and 33), and cytochrome c oxidase subunit VIb (spot 16) were all increased after WSSV infection. However, the calcium-binding protein SCP alpha chain (spot 13), WSSV infection resulted in an increase at $12 \mathrm{hpi}$, but a decrease thereafter (Figs. 1, 3A and B). The divergence between the RT-PCR and 2-DE results for this gene may be due to the different regulation mechanisms for transcription and translation.

\section{Discussion}

The aim of this study was to characterize host protein expression changes in shrimp stomach cells after WSSV infection. To do this, we combined proteomic and EST approaches to explore these interactions at the molecular level. Both of these technologies are powerful, high through-put tools that can quickly identify differentially expressed genes associated with a disease at the transcriptional and (in effect) the translational levels, respectively. A better understanding of host response to WSSV will help to elucidate this unique pathogen's mechanisms of virulence and pathogenesis, and here we identified 26 host proteins and 1 WSSV protein with altered abundance at the mRNA and/or protein levels after WSSV infection. Most of these proteins have important biological roles in the cell, and should be useful for identifying potential biomarkers as well as development of antiviral measures. We now attempt to interpret the possible biological significance of the observed infection-induced changes. 
Table 3

Increase/decrease in relative EST abundance of protein genes in the PmTwI (WSSV infected) and PmTwN (non-infected) Penaeus monodon postlarva cDNA libraries

\begin{tabular}{|c|c|c|c|c|}
\hline Spot & Gene name & $\begin{array}{l}\mathrm{PmTwI}{ }^{\mathrm{a}}(\mathrm{No} / \\
\text { percentage } \%)\end{array}$ & $\begin{array}{l}\text { PmTwN } N^{b} \text { (No } \\
\text { Percentage } \%)\end{array}$ & $\begin{array}{l}\text { Relative abundance after } \\
\text { infection }^{c}\end{array}$ \\
\hline \multicolumn{5}{|l|}{ Glycolysis } \\
\hline 32,33 & Enolase & $26 / 0.355$ & $16 / 0.235$ & 1.51 \\
\hline $41,42,48$ & Fructose-bisphosphate aldolase & $6 / 0.082$ & $3 / 0.044$ & 1.86 \\
\hline $37,38,43$ & Glyceraldehyde-3-phosphate dehydrogenase & $11 / 0.150$ & $1 / 0.015$ & 10.00 \\
\hline 44 & Phosphoglycerate mutase & $1 / 0.014$ & $0 / 0$ & $\infty$ \\
\hline 24,31 & Triosephosphate isomerase & $5 / 0.068$ & $5 / 0.073$ & 0.93 \\
\hline \multicolumn{5}{|c|}{ Calcium homeostasis } \\
\hline 2 & Calreticulin & $1 / 0.014$ & $0 / 0$ & $\infty$ \\
\hline 13 & Calcium-binding protein alpha chain & $18 / 0.245$ & $41 / 0.601$ & 0.41 \\
\hline \multicolumn{5}{|c|}{ Signaling/communication } \\
\hline 11 & $14-3-3 b$ protein & $1 / 0.014$ & $0 / 0$ & $\infty$ \\
\hline \multicolumn{5}{|c|}{ Energy production } \\
\hline 16 & Cytochrome $\mathrm{c}$ oxidase polypeptide VIb & $1 / 0.014$ & $0 / 0$ & $\infty$ \\
\hline 7 & Mitochondrial ATP synthase beta subunit & $3 / 0.041$ & $0 / 0$ & $\infty$ \\
\hline \multicolumn{5}{|l|}{ TCA cycle } \\
\hline 21 & Cytosolic malate dehydrogenase & $4 / 0.041$ & $1 / 0.015$ & 2.73 \\
\hline 30,34 & Isocitrate dehydrogenase & $3 / 0.041$ & $4 / 0.059$ & 0.69 \\
\hline \multicolumn{5}{|c|}{ Cellular component } \\
\hline 20 & Actin & $62 / 0.845$ & $66 / 0.968$ & 0.87 \\
\hline 9 & Slow tropomyosin isoform & $3 / 0.041$ & $22 / 0.322$ & 0.13 \\
\hline \multicolumn{5}{|c|}{ ATP buffering system/resistance to environmental stress } \\
\hline 35,36 & Arginine kinase & $42 / 0.572$ & $32 / 0.469$ & 1.22 \\
\hline \multicolumn{5}{|c|}{ Protein folding activity } \\
\hline 29 & Protein disulfide-isomerase & $2 / 0.027$ & $1 / 0.015$ & 1.80 \\
\hline \multicolumn{5}{|c|}{ Transportation } \\
\hline 53 & Intracellular fatty acid binding protein & $0 / 0$ & $6 / 0.088$ & 0 \\
\hline \multicolumn{5}{|c|}{ Antioxidant activity } \\
\hline 23 & Superoxide dismutase like protein & $2 / 0.027$ & $1 / 0.015$ & 1.80 \\
\hline \multicolumn{5}{|c|}{ Amino acid catabolism } \\
\hline 49 & Aspartate aminotransferase & $1 / 0.014$ & $0 / 0$ & $\infty$ \\
\hline \multicolumn{5}{|c|}{ SUMO related modification system } \\
\hline 14 & Small ubiquitin-like modifier & $2 / 0.027$ & $4 / 0.059$ & 0.46 \\
\hline \multicolumn{5}{|c|}{ Structure/mobility } \\
\hline 26 & Actin-depolymerizing factor & $0 / 0$ & $1 / 0.015$ & 0 \\
\hline \multicolumn{5}{|c|}{ Digestion related activity } \\
\hline 8 & Carboxypeptidase B & $0 / 0$ & $2 / 0.029$ & 0 \\
\hline 3,39 & Chitinase & $3 / 0.041$ & $2 / 0.029$ & 1.41 \\
\hline 12 & Chymotrypsin BI & $2 / 0.027$ & $11 / 0.161$ & 0.17 \\
\hline 10 & Preamlase & $0 / 0$ & $4 / 0.059$ & 0 \\
\hline 4,5 & Trypsin & $4 / 0.041$ & $101 / 1.480$ & 0.03 \\
\hline \multicolumn{5}{|c|}{ Major pathway for metabolite flux through the mitochondrial outer membrane } \\
\hline 51 & Voltage-dependent anion-selective channel protein 2 & $0 / 0$ & $1 / 0.015$ & 0 \\
\hline \multicolumn{5}{|c|}{ Carotenoid astaxanthin binding activity } \\
\hline 25 & Crustacyanin A2 subunit & $4 / 0.041$ & $13 / 0.101$ & 0.41 \\
\hline \multicolumn{5}{|c|}{ Nucleobase, nucleoside and nucleotide interconversion } \\
\hline 46 & Nucleoside diphosphate kinase & $37 / 0.504$ & $2 / 0.029$ & 17.38 \\
\hline \multicolumn{5}{|c|}{ ATP binding/Caspase activation } \\
\hline 17 & Valosin containing protein-1 & $1 / 0.014$ & $0 / 0$ & $\infty$ \\
\hline
\end{tabular}

${ }^{\mathrm{a}}$ Total ESTs $=7335$.

${ }^{\mathrm{b}}$ Total ESTs $=6817$

${ }^{\mathrm{c}}$ The relative abundance of a gene transcript is defined as the percentage of the ESTs matched to a gene in PmTwI divided by the percentage of the ESTs matched to the same gene in PmTwN. 


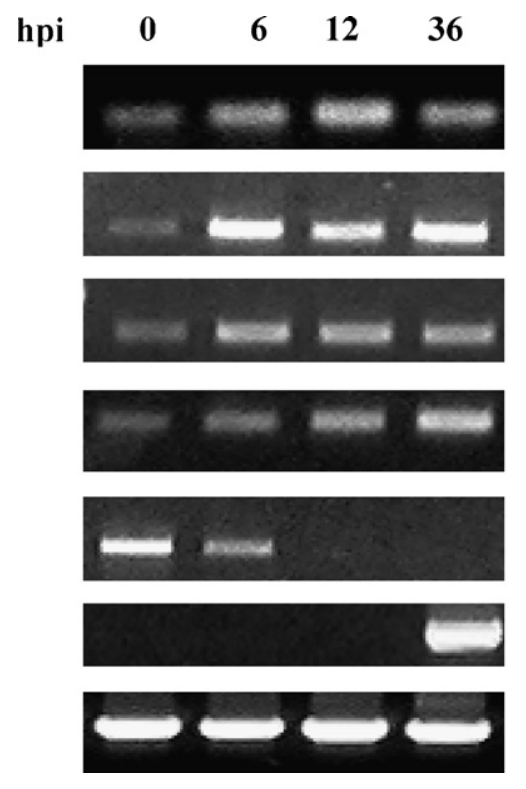

Glyceraldehyde-3-phosphate dehydrogenase

Fructose-bisphosphate aldolase

Enolase

Cytochrome c oxidase polypeptide VIb

Calcium-binding protein, SCP alpha chain

ICP11

Beta-actin

Fig. 2. Temporal RT-PCR transcription analysis for 7 selected genes. These time-course results are quite consistent with the corresponding changes in accumulated protein levels.

\subsection{Energy production}

Our present results show a marked or moderate increase in accumulated protein levels in key glycolytic enzymes (glyceraldehydes-3-phosphate dehydrogenase, fructose biphosphate aldolase and enolase). Up-regulation was also observed in the oxygen carrier hemocyanin, in the electron transport chain protein cytochrome $\mathrm{c}$ oxidase polypeptide VIb (a subunit of cytochrome oxidase, the terminal enzyme of the respiratory chain that transfers electrons to molecular oxygen, which then reacts with hydrogen ions to form water), and in both the alpha and beta subunits of mitochondrial ATP synthase. Taken together, the increased availability of oxygen and the increased levels of some key glycolytic enzymes and oxidative respiration enzymes would suggest that oxidative respiration was enhanced in WSSV-infected cells. If so, this would allow the infected cells to increase their energy yield by extracting energy from glucose through aerobic respiration to yield ATP. Bearing in mind that WSSV is an extremely virulent pathogen with a very rapid onset [4], it seems probable that the up-regulation of these energy production-related proteins might not only meet the requirement of a large burst of oxygen and energy during rapid virus replication, but would also facilitate energy-dependent detoxification (which would help the cells tolerate the environmental changes caused by WSSV infection) as well as other energy-dependent biological processes. Improving the survival capability of the infected cells also benefits WSSV because cell-survival is essential for successful virus replication.

\subsection{Nucleic acid synthesis}

In addition to energy production, we also note that several of the proteins that are up-regulated after WSSV infection have roles in energy-dependent processes. For example, when nucleotide triphosphates (NTPs) are synthesized from nucleotide diphosphates (NDPs), the high-energy phosphate transfer from ATP proceeds via the phosphorylated NDP kinases, and NDP kinase is up-regulated after WSSV infection. NDP kinases provide NTPs for nucleic acid synthesis, CTP for lipid synthesis, UTP for polysaccharide synthesis and GTP for protein elongation, signal transduction and microtubule polymerization. NDP kinases are also involved in cell growth, differentiation, and tumor metastasis [36], and the control of endocytosis through the regulation of dynamin [37]. All of these functions are potentially important for WSSV replication. 

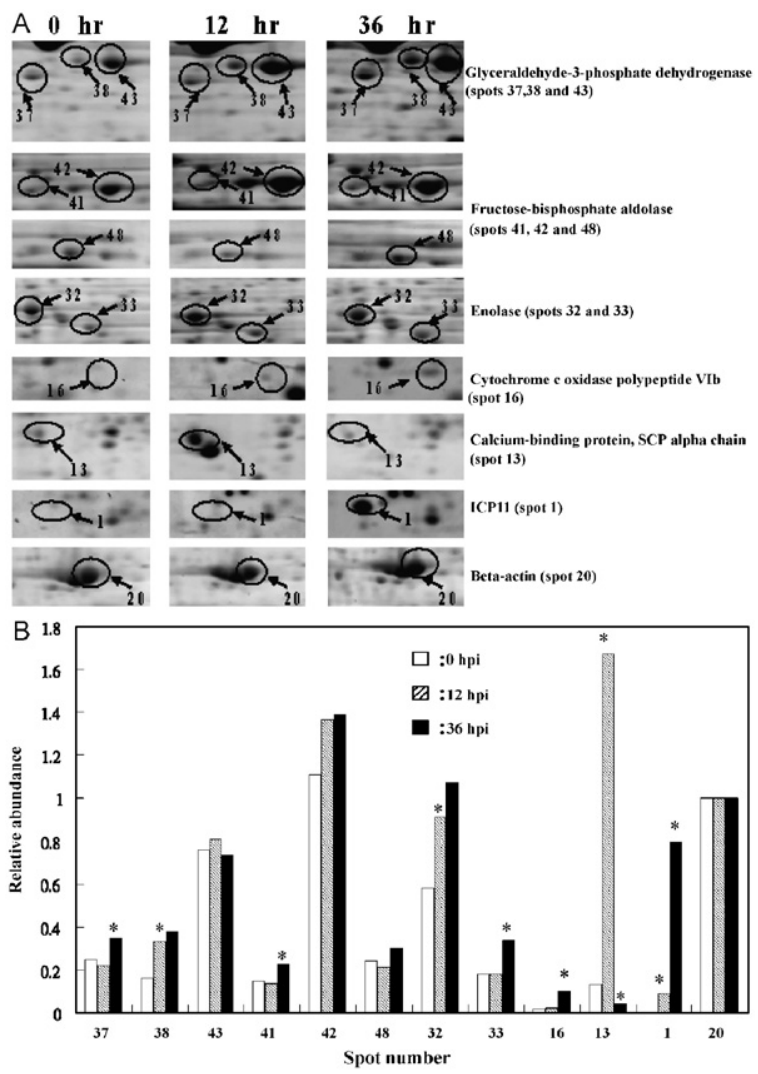

Fig. 3. Temporal 2-DE profiles and quantitative relative abundance for the same 7 genes (12 spots) shown in Fig. 2. (A) 2-DE spots of shrimp stomachs experimentally infected with WSSV for the indicated times. The WSSV non-structural protein ICP11 and beta-actin are also shown and used as reference proteins. (B) Plotted data represent the intensity of each protein spot after normalization relative to the beta-actin protein intensity (spot 34) in the same gel. Each bar represents the average relative abundance of 2 -DE gels from two independent experiments. An asterisk indicates a marked $(>50 \%)$ increase or decrease relative to the immediately previous sampling time.

\subsection{Calcium homeostasis}

Through the course of the virus infection cycle, the intracellular $\mathrm{Ca}^{2+}$ concentration is critical for events such as virus infection and capsid transportation to the nucleus [38]. Moreover, increases in intracellular $\mathrm{Ca}^{2+}$ concentration have been associated with many host cell defense responses, such as apoptosis. The modulation of calcium related proteins during WSSV infection is, therefore, likely to be important.

Our present results show the protein expression levels of three calcium-related proteins were altered after WSSV infection. Expression of sarco/ER-type calcium pump-ER $\mathrm{Ca}^{2+}$-ATPase was up regulated about 7-fold. This protein is located on the ER membrane and its function is to refill the ER with $\mathrm{Ca}^{2+}$. Another up-regulated protein, calreticulin, is an important molecular chaperone involved in "quality control" within secretory pathways. This protein is also involved in the regulation of intracellular $\mathrm{Ca}^{2+}$ homeostasis and it increases the $\mathrm{Ca}^{2+}$ storage capacity of the ER [39]. The third calcium-related protein, invertebrate SCP (SCPalpha chain) was down regulated. SCP-alpha chain has three $\mathrm{Ca}^{2+}$-binding sites that are common to EF-hand-type $\mathrm{Ca}^{2+}$-binding proteins. The EF-hand calcium-binding proteins have remarkable sequence homology and structural similarity, and they function in $\mathrm{Ca}^{2+}$ buffering. A decrease in the accumulated levels of a protein in this family might, therefore, disrupt normal physiological function by interfering with the $\mathrm{Ca}^{2+}$-dependent signaling pathway [40,41], but it is interesting that several WSSV proteins (e.g. the proteins encoded by WSSV ORFs 136 and 486 in GenBank Accession No AF440570) contain an EF-hand calcium-binding motif that would allow them to take over this function.

\subsection{Voltage-dependent anion-selective channel}

Another up-regulated protein was the voltagedependent anion channel (VDAC). In addition to providing the major pathway for metabolite flux through the outer mitochondrial membrane, VDAC also binds to any hexokinase (HK) that translocates to the mitochondrial membrane. VDAC-bound HK is then able to use intramitochondrial ATP to phosphorylate glucose, which is the first step of glycolysis [42,43]. VDAC-bound HK also has an anti-apoptotic function $[44,45]$, but even through apoptosis is inhibited in WSSV-infected cells [27], we did not find any evidence here that HK was upregulated.

\subsection{Cellular signaling}

14-3-3b protein was also up-regulated after WSSV infection. Proteins in the 14-3-3 family are involved in cellular processes such as signal transduction, cell-cycle control, apoptosis, stress response and malignant transformation by binding to specific phosphorylated sites on diverse target proteins $[46,47]$. In our previous study (Wu et al., submitted), we found that WSSV infection led to elevated 14-3-3 protein levels in lymphoid organ cells and, to a lesser extent, in stomach cells as well. 
However, in the lymphoid cells, up-regulation of 14-3-3 protein was related to apoptosis, whereas in the stomach cells, apoptosis did not occur. All these results show that 14-3-3 proteins are up-regulated in stomach cells, but suggest that the up-regulation of 14-3-3b protein is not related to apoptosis. Instead, we tentatively conclude that it must be related to other cellular processes that are often modulated during virus infection, such as, for instance, cellcycle control.

\subsection{Possible multifaceted roles of glycolytic enzymes: GAPDH, fructose biphosphate aldolase and enolase}

As noted above, the protein profiling of WSSVinfected cells revealed an increase in GAPDH and fructose biphosphate aldolase (aldolase) proteins and their corresponding mRNAs. GAPDH is one of the key enzymes in the glycolysis pathway. After aldolase breaks fructose-1,6-diphosphate into glyceraldehyde-3-phosphate (G3P) and dihydroxyacetone phosphate, GAPDH oxidizes G3P and reduces $\mathrm{NAD}^{+}$to NADH. This not only facilitates energy production but also creates a reducing environment to protect macromolecules from being damaged by free radical/reactive oxygen species during virus infection. There was also an increase in another $\mathrm{NAD}^{+} / \mathrm{NADH}$-dependent enzyme, isocitrate dehydrogenase, which is additional evidence of the importance of NADH in the WSSV-infected cells. Lastly, an increase in the levels of NADH would be useful to WSSV because such a large virus would be expected to use the cell machinery to synthesize many organic molecules, and NADH can supply the reducing equivalents that are critical for the biogenesis of carbohydrates and fats.

An increasing number of diverse non-glycolytic activities of GAPDH have been reported, including macromolecular transport, microtubule bundling, nuclear tRNA transport and apoptosis $[48,49]$. GAPDH has also been variously implicated in virus infections: in the replication of Hepatitis Delta Virus, GAPDH interacts with viral RNA and enhances ribozyme catalysis [50], and it has also been reported that the GAPDH mRNA level of human adherent monocytes is markedly increased during vaccinia virus infection [49]. GAPDH interacts with multi-function $14-3-3$ proteins in plants [51] and it is curious to note that the expression of a 14-3-3-like protein also increased after WSSV infection, although there is not yet any evidence that this binds with GAPDH to regulate apoptosis or any other of its multi-functions.

Finally, it has recently been shown that the muscle-specific calmodulin-dependent protein kinase forms a complex with the glycolytic enzymes GAPDH, aldolase and enolase at the sacroplasmic reticulum membrane [52]. This may provide another mechanism for controlling $\mathrm{Ca}^{2+}$ release and signaling. Since we have shown here that GAPDH, aldolase and enolase are the only three glycolytic enzymes to be up-regulated (at both the mRNA and protein levels) during WSSV infection, it will be interesting to determine whether such a complex exists in WSSV-infected cells.

In conclusion, the results presented here are basic data that will be a useful starting point for many subsequent studies. In particular, the proteome maps (Fig. 1), which were very consistent across multiple replications, should provide a reliable baseline reference for identifying potential biomarkers in future immuno-stimulant or vaccination studies, as well as in assays of anti-viral drugs.

\section{Acknowledgments}

This investigation was supported financially by National Science Council grants (NSC94-2317B-002-010 and NSC94-2311-B-002-021). Proteomic mass spectrometry analyses were performed by the Core Facilities for Proteomics Research located at the Institute of Biological Chemistry, Academia Sinica. The authors would like to thank Prof. S.H. Chiou for technical support of 2-DE work. We are also indebted to Paul Barlow for his helpful criticism.

\section{References}

[1] Chou HY, Huang CY, Wang CH, Chiang HC, Lo CF. Pathogenicity of a baculovirus infection causing white spot syndrome in cultured penaeid shrimp in Taiwan. Dis Aquat Organ 1995;23:165-73.

[2] Flegel TW. Special topic review: major viral diseases of black tiger prawn (Penaeus monodon) in Thailand. World $\mathbf{J}$ Microbiol Biotechnol 1997;13:433-42.

[3] Inouye $\mathrm{K}$, Miwa $\mathrm{S}$, Oseko $\mathrm{N}$, Nakano $\mathrm{H}$, Kimura $\mathrm{T}$, Momoyama K, et al. Mass mortalities of cultured kuruma shrimp Penaeus Japonicus in Japan in 1993 -electronmicroscopic evidence of the causative virus. Fish Pathol 1994;29:149-58.

[4] Lo CF, Leu JH, Ho CH, Chen CH, Peng SE, Chen YT, et al. Detection of baculovirus associated with white spot syn- 
drome (WSBV) in penaeid shrimps using polymerase chain reaction. Dis Aquat Organ 1996;25:133-41.

[5] Momoyama K, Hiraoka M, Nakano H, Koube H, Inouye K, Oseko N. Mass mortalities of cultured kuruma shrimp, Penaeus japonicus, in Japan in 1993-Histopathological Study. Fish Pathol 1994;29:141-8.

[6] Nakano H, Koube H, Umezawa S, Momoyama K, Hiraoka $\mathrm{M}$, Inouye $\mathrm{K}$, et al. Mass mortalities of cultured kuruma shrimp, Penaeus-Japonicus, in Japan in 1993 -epizootiological survey and infection trials. Fish Pathol 1994;29: 135-9.

[7] Takahashi Y, Itami T, Kondo M, Maeda M, Fujii R, Tomonaga $\mathrm{S}$, et al. Electron microscopic evidence of bacilliform virus infection in kuruma shrimp (Penaeus japonicus). Fish Pathol 1994;29:121-5.

[8] Wang CH, Lo CF, Leu JH, Chou CM, Yeh PY, Chou HY, et al. Purification and genomic analysis of baculovirus associated with white spot syndrome (WSBV) of Penaeus monodon. Dis Aquat Organ 1995;23:239-42.

[9] Wongteerasupaya C, Vickers JE, Sriurairatana S, Nash GL, Akarajamorn A, Boonsaeng $\mathrm{V}$, et al. A non-occluded, systemic baculovirus that occurs in cells of ectodermal and mesodermal origin and causes high mortality in the black tiger prawn Penaeus monodon. Dis Aquat Organ 1995;21:69-77.

[10] Chen LL, Wang HC, Huang CJ, Peng SE, Chen YG, Lin SJ, et al. Transcriptional analysis of the DNA polymerase gene of shrimp white spot syndrome virus. Virology 2002;301:136-47.

[11] van Hulten MC, Witteveldt J, Peters S, Kloosterboer N, Tarchini R, Fiers M, et al. The white spot syndrome virus DNA genome sequence. Virology 2001;286:7-22.

[12] Yang F, He J, Lin X, Li Q, Pan D, Zhang X, et al. Complete genome sequence of the shrimp white spot bacilliform virus. J Virol 2001;75:11811-20.

[13] Tsai JM, Wang HC, Leu JH, Hsiao HH, Wang AH, Kou $\mathrm{GH}$, et al. Genomic and proteomic analysis of thirty-nine structural proteins of shrimp white spot syndrome virus. J Virol 2004;78:11360-70.

[14] Tsai JM, Wang HC, Leu JH, Wang AH, Zhuang Y, Walker $\mathrm{PJ}$, et al. Identification of the nucleocapsid, tegument, and envelope proteins of the shrimp white spot syndrome virus virion. J Virol 2006;80:3021-9.

[15] Leu JH, Tsai JM, Wang HC, Wang AH, Wang CH, Kou $\mathrm{GH}$, et al. The unique stacked rings in the nucleocapsid of the white spot syndrome virus virion are formed by the major structural protein VP664, the largest viral structural protein ever found. J Virol 2005;79:140-9.

[16] Valk JM, Bonami JR, Flegel TW, Kou GH, Lightner DV, Lo CF, et al. Nimaviridae. In: Fauquet CM, Mayo MA, Maniloff J, Desselberger U, Ball LA, editors. VIIIth report of the international committee on taxonomy of viruses. Amsterdam: Elsevier Press; 2004. p. 187-92.

[17] Astrofsky KM, Roux MM, Klimpel KR, Fox JG, Dhar AK. Isolation of differentially expressed genes from white spot virus (WSV) infected Pacific blue shrimp (Penaeus stylirostris). Arch Virol 2002;147:1799-812.

[18] Bangrak P, Graidist P, Chotigeat W, Supamattaya K, Phongdara A. A syntenin-like protein with postsynaptic density protein (PDZ) domains produced by black tiger shrimp Penaeus monodon in response to white spot syndrome virus infection. Dis Aquat Organ 2002;49:19-25.
[19] Dhar AK, Dettori A, Roux MM, Klimpel KR, Read B. Identification of differentially expressed genes in shrimp (Penaeus stylirostris) infected with White spot syndrome virus by cDNA microarrays. Arch Virol 2003;148:2381-96.

[20] Gross PS, Bartlett TC, Browdy CL, Chapman RW, Warr GW. Immune gene discovery by expressed sequence tag analysis of hemocytes and hepatopancreas in the Pacific white shrimp, Litopenaeus Vannamei, and the Atlantic white shrimp, L. setiferus. Dev Comp Immunol 2001;25:565-77.

[21] He N, Qin Q, Xu X. Differential profile of genes expressed in hemocytes of white spot syndrome virus-resistant shrimp (Penaeus japonicus) by combining suppression subtractive hybridization and differential hybridization. Antiviral Res 2005;66:39-45.

[22] Pan D, He N, Yang Z, Liu H, Xu X. Differential gene expression profile in hepatopancreas of WSSV-resistant shrimp (Penaeus japonicus) by suppression subtractive hybridization. Dev Comp Immunol 2005;29:103-12.

[23] Rojtinnakorn J, Hirono I, Itami T, Takahashi Y, Aoki T. Gene expression in haemocytes of kuruma prawn, Penaeus japonicus, in response to infection with WSSV by EST approach. Fish Shellfish Immunol 2002;13:69-83.

[24] Roux MM, Pain A, Klimpel KR, Dhar AK. The lipopolysaccharide and beta-1,3-glucan binding protein gene is upregulated in white spot virus-infected shrimp (Penaeus stylirostris). J Virol 2002;76:7140-9.

[25] Lo CF, Ho CH, Chen CH, Liu KF, Chiu YL, Yeh PY, et al. Detection and tissue tropism of white spot syndrome baculovirus (WSBV) in captured brooders of Penaeus monodon with a special emphasis on reproductive organs. Dis Aquat Organ 1997;30:53-72.

[26] Tsai MF, Kou GH, Liu HC, Liu KF, Chang CF, Peng SE, et al. Long-term presence of white spot syndrome virus (WSSV) in a cultivated shrimp population without disease outbreaks. Dis Aquat Org 1999;38:107-14.

[27] Wu JL, Muroga K. Apoptosis does not play an important role in the resistance of 'immune' Penaeus japonicus against white spot syndrome virus. J Fish Dis 2004;27:15-21.

[28] Bangrak P, Graidist P, Chotigeat W, Phongdara A. Molecular cloning and expression of a mammalian homologue of a translationally controlled tumor protein (TCTP) gene from Penaeus monodon shrimp. J Biotechnol 2004;108: 219-26.

[29] Luo T, Zhang X, Shao Z, Xu X. PmAV, a novel gene involved in virus resistance of shrimp Penaeus monodon. FEBS Lett 2003;551:53-7.

[30] Zhang X, Huang C, Qin Q. Antiviral properties of hemocyanin isolated from shrimp Penaeus monodon. Antiviral Res 2004;61:93-9.

[31] O'Farrell PH. High resolution two-dimensional electrophoresis of proteins. J Biol Chem 1975;250:4007-21.

[32] Bjellqvist B, Kristina EK, Righetti PG, Gianazza E, Görg A, Westermeier R, et al. Isoelectric focusing in immobilized ph gradients: principle, methodology and some applications. J Biochem Biophys Methods 1982;6:317-39.

[33] Lo CF, Hsu HC, Tsai MF, Ho CH, Peng SE, Kou GH, et al. Specific genomic DNA fragment analysis of different geographical clinical samples of shrimp white spot syndrome virus. Dis Aquat Organ 1999;35:175-85.

[34] Wu JL, Suzuki K, Arimoto M, Nishizawa T, Muroga K. Preparation of an inoculum of white spot syndrome virus for challenge tests in Penaeus japonicus. Fish Pathol 2002;37:65-9. 
[35] Kanehisa M, Goto S. KEGG: kyoto encyclopedia of genes and genomes. Nucleic Acids Res 2000;28:27-30.

[36] Kimura N, Shimada N, Fukuda M, Ishijima Y, Miyazaki H, Ishii A, et al. Regulation of cellular functions by nucleoside diphosphate kinases in mammals. J Bioenerg Biomembr 2000;32:309-15.

[37] Narayanan R, Ramaswami M. Regulation of dynamin by nucleoside diphosphate kinase. J Bioenerg Biomembr 2003;35:49-55.

[38] Cheshenko N, Del Rosario B, Woda C, Marcellino D, Satlin LM, Herold BC. Herpes simplex virus triggers activation of calcium-signaling pathways. J Cell Biol 2003;163:283-93.

[39] Gelebart P, Opas M, Michalak M. Calreticulin, a $\mathrm{Ca}^{2+}$. binding chaperone of the endoplasmic reticulum. Int $\mathrm{J}$ Biochem Cell Biol 2005;37:260-6.

[40] Rabah G, Popescu R, Cox JA, Engelborghs Y, Craescu CT. Solution structure and internal dynamics of NSCP, a compact calcium-binding protein. FEBS J 2005;272:2022-36.

[41] Takagi T, Konishi K. Amino acid sequence of alpha chain of sarcoplasmic calcium binding protein obtained from shrimp tail muscle. J Biochem (Tokyo) 1984;95:1603-15.

[42] Golshani-Hebroni SG, Bessman SP. Hexokinase binding to mitochondria: a basis for proliferative energy metabolism. J Bioenerg Biomembr 1997;29:331-8.

[43] Pastorino JG, Hoek JB. Hexokinase II: the integration of energy metabolism and control of apoptosis. Curr Med Chem 2003;10:1535-51.

[44] Bryson JM, Coy PE, Gottlob K, Hay N, Robey RB. Increased hexokinase activity, of either ectopic or endogenous origin, protects renal epithelial cells against acute oxidant-induced cell death. J Biol Chem 2002;277: $11392-400$.
[45] Gottlob K, Majewski N, Kennedy S, Kandel E, Robey RB, Hay N. Inhibition of early apoptotic events by Akt/PKB is dependent on the first committed step of glycolysis and mitochondrial hexokinase. Genes Dev 2001;15: 1406-18

[46] Mackintosh C. Dynamic interactions between 14-3-3 proteins and phosphoproteins regulate diverse cellular processes. Biochem J 2004;381:329-42.

[47] van Hemert MJ, Steensma HY, van Heusden GP. 14-3-3 proteins: key regulators of cell division, signaling and apoptosis. BioEssays 2001;23:936-46.

[48] Ishitani R, Chuang DM. Glyceraldehyde-3-phosphate dehydrogenase antisense oligodeoxynucleotides protect against cytosine arabinonucleoside-induced apoptosis in cultured cerebellar neurons. Neurobiology 1996;93:9937-41.

[49] Nahlik KW, Mleczko AK, Gawlik MK, Rokita HB. Modulation of GAPDH expression and cellular localization after vaccinia virus infection of human adherent monocytes. Acta Biochim Pol 2003;50:667-76.

[50] Lin SS, Chang SC, Wang YH, Sun CY, Chang MF. Specific interaction between the hepatitis delta virus RNA and glyceraldehyde 3-phosphate dehydrogenase: an enhancement on ribozyme catalysis. Virology 2000;271:46-57.

[51] Huber SC, MacKintosh C, Kaiser WM. Metabolic enzymes as targets for 14-3-3 proteins. Plant Mol Biol 2002;50: 1053-63.

[52] Singh P, Salih M, Leddy JJ, Tuana BS. The muscle-specific calmodulin-dependent protein kinase assembles with the glycolytic enzyme complex at the sarcoplasmic reticulum and modulates the activity of glyceraldehyde-3-phosphate dehydrogenase in a $\mathrm{Ca}^{2+} /$ calmodulin-dependent manner. J Biol Chem 2004;279:35176-282. 